\title{
Offene Korrespondenz
}

Worms. Ein Handgriff, der mir ímmer gate Dienste geleistet hatund, wie es scheint, nicht $\Lambda$ veiter bekannt ist, dürfte deshalb vielleicht derVeröffentliehung wert sein und auch anderen niitzlich werden. - Man hatbei kleinen und unbedeutenden, aber häufig notwendigen Eingriffen am Auge, z. B. Entfernung von Fremdkörpern aus der Hornhaut und Konjunktiva undAhnlichem, nicht immer eine Assistenz zur Hand, die das obere Lid in dieHöhe hebt, da der Sperrlidhalter bei den Patienten ein sehr unbeliebtes, siemeist sogar ängstigendes und auch wenig handliches Instrument ist. Insolchen Fallen nun, ganz besonders dann, wenn seitliche Beleuchtung not-, wendig ist, lasse ich den Kranken selbst das obere Lid in die Höhe hebenund fixieren, und zwar derart, das derselbe von oben und hinten her ñberseinen Kopf weg mit dem Mittel- odor Zeigetinger - oder beiden - derlinken Hand das rechte und eventuell ebenso mit der rechten das linkeOberlid erhebt und festhält, wobei - - durch den Griff von hinten undoben her - die fixierende Hand samt Arm des Patient-Assistenten derartbeiseite liegt, dass sie durchaus nicht geniert oder beengt. Die moistenKranken bringen diesen Handgriff leicht und richtig fertig. Man erhitlt da-durch die linke Hand ganz frei zum Halten der Beïeuchtungslinse und zumgleichzeitigen Herabziehen des unteren Lides (mit dem 5. oder 4. Fingerderselben), während man mit der rechten Hand das Instrument handhabt.Ein weiterer Vorteil erwächst bei diesem Handgriff noch daraus, dass derKranke ruhiger ist and leichter still halt, weil er seine ganze Aufmerk-samkeit auf die Haltung seiner Hand und Finger behuí's Fixierung des

Lideskonzentrieren muss. Medizinalrat Dr. Baas-Worms.

Amsterdam. Übßr Cinehonin-Intoxikation. Berichtigung.

Infolge eines freundlichen Schreibens des Herrn Prof. Le $\Lambda$ vin bin ich in der Lage, zu beriehten, dass das von mir behaiipteto Niclit-Erwähntsein des

Ofiene Korrespondenz.

275

Cinchonins in seinem Werk $\theta$ über „Die Nebenwirkungen der Arznei-Mittel” sich nur auf ältere Auflagen be?iehen darf, wie ich eine solche aus der hiesigen Bibliothek bezogen hatte. In der neuesten Àuflage findet man darin «in ganzes Kapitel über Cinchonin. Freilich wird nicbt von Sehstörungen berichtet: diese finden aber Erwähnung als „Gesichtsverdunkelung” in Lewíns „Toxikologie” 1897, 2. Aufl., S. 310. - Weiler verdanke ich Herrn Dr. Bouvin (im Haag) die Einsicht eines Buches von G. E. de Schweinitz ..The toxie amblyopias" (1896, Philadelphia). In deniselben werden nach Beschreibung der Chinin-Amaurosis Versuche an Hunden mit Cinchonin be-schrieben. Die Tatsache, auf welche ich in meinem Aufsatze über Cinchoniníntoxikation hi $\prod \Lambda$ veisen wollte, war die, dass diese A.rznei keine retinalen Syptome verursacht, wohl aber die Funktion des Ciliar-Muskels herabgesetzt hatte, während bekanntlich das Chinin in erster Linie die Netzhaut angreift. Ich schloss daraus, dass man Kranken, welchen Chinin wegen überstandener Intoxikation verboten ist, Cinchonin verschreiben darf, und sprach die Iloffnung aus, dass das letztere Mittel vielleicht nur die Uvea angreifen werde, und nicht die Netzhaut. Diese Hoffnung muss man nach de Schweinitz Versuchen aufgeben, denn dieser Autor sah die Blindheit ebensogut nach Cinchonin- als nach Chinin·Verbrauch folgen, wenn auch die 
giftige Dosís bedeutend grosser war (S. 199). Dass bei seinen Versuchen keine Akkommodations-Parese der Blindheit vorausging, ist selbstverständlich, weil die Ver-suchstiere Hunde waren. $-\Lambda$ Venn man also Kranken mit Idiosynkrasie gegen Chinin nicht ganz ohne Gefahr Cinchonin verschreiben kann, so bleibt doch der Yersuch erlaubt, zumal wenn sich die Beobachtung bestätigt, dass uns eine Akkomodations-Parese vor clem Ausbruch der Intoxikation warnt, eine Warming, welche beim Chinin-Verbrauch völlig vermisst wird.

Dr. G. J, Schoute-Amsterdam.

X. internalionaler OphthalmologenkongFess in LuzeFП, 18. Sept. 1904.

Ausstellung .

Das Komitee des X. internationalen Kongresses für Ophthalmologie hat mich beauftragt, Sorge zu tragen für eine zweckmässige Ausstellung aller dem Kongresse übermittelten wissenschaftlichen Apparate, Instrumente, sowie der verschiedenen Lehr- und Unterrichtsmittel. I. Ich ersuche daher alle Kollegen sowie alle wissenschaftlichen optischen wie mechanischen Firmen die irgendwelche Objekte am internationalen Ophthalmologenkongresse in Luzern auszustellen wünschen

sich bis zum 1. Juli 1904 an mich zu wenden mit der genauen Angabe der Ausstellungs-objekte des gewünschten Raumes

sowie der Art und Stiirke der allenfalls benötigten elektrischen Kraft. Später angemeldete Ausstellungsobjekte konnen nur noch in clem Masse Berücksichtigung finden als der noch verfügbare Kaum es gestattet. 